\title{
Biosorption optimization and equilibrium isotherm of industrial dye compounds in novel strains of microscopic fungi
}

\author{
K. Rybczyńska-Tkaczyk ${ }^{1} \cdot$ T. Korniłłowicz-Kowalska ${ }^{1}$
}

Received: 10 May 2016/Revised: 18 August 2016/Accepted: 13 September 2016/Published online: 22 September 2016

(C) The Author(s) 2016. This article is published with open access at Springerlink.com

\begin{abstract}
The aim of this study was to evaluate the biosorption capacity of selected strains of microscopic fungi. We optimized the biosorption process and used the Freundlich isotherm for three strains: H. haematococca BwIII43, K37 and T. harzianum BsIII33 to describe the biosorption equilibrium of anthraquinone dye, Alizarin Blue Black B (ABBB) and alkali lignin (AL). In optimal conditions $\left(1 \mathrm{~g}\right.$ of mycelium biomass, $\left.\mathrm{pH}=7.0,28{ }^{\circ} \mathrm{C}\right)$ for $\mathrm{ABBB}$ and $\mathrm{AL}$ sorption, the live biomass of H. haematococca BwIII43 was characterized by a higher sorption capacity, amounting to 247.47 and $161.00 \mathrm{mg} \mathrm{g}^{-1}$, respectively. The highest sorption properties toward anthraquinone dye $\left(K_{\mathrm{F}}=19.96 \mathrm{mg} \mathrm{g}^{-1}\right)$ were shown for the biomass of $H$. haematococca K37. In the presence of alkali lignin, the highest sorption capacity and bond strength exhibited the biomass of $H$. haematococca BwIII43 ( $\left.K_{\mathrm{F}}=28.20 \mathrm{mg} \mathrm{g}^{-1}, n=3.46\right)$. Effective decolorization of ABBB and AL by the selected strains of microscopic fungi indicated that the biosorption process additionally enhanced the removal of color compounds from the solution.
\end{abstract}

Keywords Biosorption · Kraft lignin · Anthraquinone dye · Freundlich isotherm

Editorial responsibility: M. Abbaspour.

K. Rybczyńska-Tkaczyk

kamila.rybczynska-tkaczyk@up.lublin.pl

1 Department of Environmental Microbiology, Laboratory of Mycology, The University of Life Sciences, ul. Leszczyńskiego 7, Lublin 20-069, Poland

\section{Introduction}

Dye wastewater from textile and dyestuff industries is one of the most difficult industrial wastewaters to treat. Textile dyes are one of organic substances, which effects on humans, animals and different ecosystems have been demonstrated. These pollutants can be transferred to the food chain, and thus, they pose a threat to human health (Banat et al. 1996). Dye wastewater is usually treated by physical or chemical treatment processes, but these technologies are generally ineffective in color removal, expensive and less adaptable to a wide range of dye wastewaters (Mona et al. 2011). Therefore, there is an increasing demand for efficient and economical technologies removing dyes from wastewater. A wide variety of fungi, especially white-rot fungi, are capable of removing a wide range of dyes from industrial wastewaters (Fu and Viraraghavan 2001, 2002a, b). Recently, decolorization ability of microscopic fungi has been reported (Korniłłowicz-Kowalska and Rybczyńska 2014; Rybczyńska and Korniłłowicz-Kowalska 2015). Previous data have demonstrated that fungal biomass also demonstrates the biosorption ability of industrial dye ( $\mathrm{Fu}$ and Viraraghavan 2002a, b). In addition to biodegradation, biosorption mechanisms may play an important role in the decolorization of dyes by living fungi. Biosorption is considered as one of the leading dye wastewater treatment techniques in terms of costs and operation. Biosorption is a physicochemical process involving many mechanisms, including absorption, adsorption, ion exchange, surface complexation and precipitation. Biosorption processes are highly important in the environment and conventional biotreatment processes (Ali 2010, 2012, 2014; Ali et al. 2012; Ali and Gupta 2007; Aretxage et al. 2001; Fomina and Gadd 2014). In recent years, there has been an 
increasing interest in the ligninolytic capabilities of microfungi, which, similarly to the white-rot fungi, can remove a broad spectrum of aromatic compounds from wastewater. There are various fungi, other than white-rot fungi, such as Aspergillus niger, Aspergillus terreus, Rhizopus arrhizus, Rhizopus oryzae, Penicillium sp., Trichoderma harzianum and Haematonectria haematococca, which can also remove diverse dyes through biosorption (Almeida and Corso 2014; $\mathrm{Fu}$ and Viraraghavan 2000, 2001, 2002b; Gallagher et al. 1997; O’Mahony et al. 2002; Yang et al. 2011; Zhou and Banks 1991).

Adsorption of dyes by living and dead fungal biomass is dependent on dye properties, such as molecular structure and type or the number and position of substituents in the dye molecule (Reife and Freeman 1996). However, decolorization with active biomass provides better results, most likely due to the parallel dye compound removal (Aretxage et al. 2001). By using the growing cultures in dye removal, one can avoid the need for a separate biomass production process, including cultivation, harvesting, drying, processing and storage prior to use. It also allows to grow the biomass and remove the dyes in the same step, leading to a simpler system control and lower operational costs (Aksu 2005; Xin et al. 2010). Recently, biosorption was suggested as a first step, prior to microbial treatment, to concentrate the dye (Aretxage et al. 2001; Nigam et al. 2000). Biosorption by the biomass is the result of Van der Waals physical interactions and chemical properties of ionic and covalent bonds.

Cell walls consist mainly of polysaccharides, proteins and lipids with functional groups. Dyes can interact with these active groups on the mycelium surface. The advantage of this process is the ability to remove high concentrations of dyes from aqueous solutions, inexpensive production costs of biomass and the possibility of removing toxic compounds. Interactions between the dye compounds and biosorbent are dependent on chemical structures, properties and molecular mass (Crini 2006; Polman and Brekenridge 1996; Reife and Freeman 1996; Robinson et al. 2001). Adsorption is increased by the presence of hydroxyl, nitro and azo groups in the dye molecule, but decreased by sulfonic acid groups (Reife and Freeman 1996). The relationship between the concentration of the dye and its sorption by the mycelium under optimal conditions is described by the thermodynamic relationship known as adsorption isotherms. Experimental determination of adsorption isotherms can describe the adsorption properties of biosorbents.

The Freundlich adsorption isotherm is most commonly used to describe the physical relationship between the mycelium and dyes (Fu and Viraraghavan 2000; Zeroual et al. 2006). The Freundlich isotherm assumes a heterogeneous surface. Using an equation, Freundlich has characterized the biosorption of Reactive Blue 140 and Direct Blue 1 by the living mycelium of Aspergillus niger and Trametes versicolor (Bayramoglu and Arica 2007; Karthikeyan et al. 2009).

The aim of this study was to comprehensively evaluate the sorption capacity of living biomass of microscopic fungi, showing high decolorization activity against Alizarin Blue Black B anthraquinone dye. Optimization of sorption conditions of aromatic compounds: Alizarin Blue Black B and alkali lignin was conducted for three selected strains of microscopic fungi: H. haematococca BwIII43, K37 and T. harzianum BsIII33, demonstrating the highest sorption properties during decolorization processes. Optimization step was followed by the Freundlich isotherm determination. In this study was first reported ability to alkali lignin biosorption by live microscopic fungi biomass.

\section{Materials and methods}

\section{Strains of microscopic fungi}

The strains were isolated from the samples of black earth soil (Phaeozem, FAO classification) from a field near Lublin (southeastern Poland). Isolation of fungi from the soil was conducted using a alkali lignin as the substrate. The isolation and selection procedure has been previously described by Korniłłowicz-Kowalska and Rybczyńska (2014). Lignin $(10 \mathrm{~g})$ in polyamide- 6 bags $(5 \times 5 \times 6 \mathrm{~cm}$, pores of $0.5 \mathrm{~mm}$ ) was introduced to glass vessels with a volume of $1000 \mathrm{~cm}^{3}$ filled with soil to a depth of ca. $5 \mathrm{~cm}$ from the soil surface. The study included 52 strains of micromycetes isolated from alkali lignin. These strains were characterized by an effective decolorization of the agar medium containing Alizarin Blue Black B as an indicator. The selected strains represented 7 following species: Haematonectria haematococca (25 strains), Clonostachrys rosea f. catenulata (16), Clonostachrys rosea f. rosea (5), Aspergillus spp. (3), Phaeostalagmus cyclosporus (1), Absidia spinosa (1) and Trichoderma harzianum (1) (Korniłłowicz-Kowalska and Rybczyńska, 2014).

\section{Dye compounds}

Lignin (conventionally referred to as the alkali lignin) was obtained from the Cellulose Plant Stora Enso as a solid material precipitated from the first alkaline fraction with $98 \% \mathrm{H}_{2} \mathrm{SO}_{4}$ (Ostrołęka, Poland). Prior to use, lignin was dissolved in $0.1 \mathrm{M} \mathrm{NaOH}$. Basic chemical properties of that fraction were as follows $\left(\mathrm{g} \mathrm{kg}^{-1}\right.$ dry matter): 408.2 carbon, 40.4 hydrogen and 0.2 nitrogen. Alizarin Blue Black B was used in the analyses (Sigma). Alizarin Blue 
Black B (ABBB) is the anthraquinone-type dye. This dye is classified as a mordant anionic dye.

\section{Culture conditions}

The experiments were conducted in static cultures in 100 $\mathrm{cm}^{3}$ Erlenmeyer flasks containing $50 \mathrm{~cm}^{3}$ of liquid medium (Korniłłowicz-Kowalska and Rybczyńska 2014) with $0.25 \%$ glucose and $0.03 \%$ Alizarin Blue Black B anthraquinone dye $(30 \mathrm{mg} \mathrm{ABBB} / 100 \mathrm{ml})$ and $0.2 \%$ alkali lignin $(200 \mathrm{mg} / 100 \mathrm{ml})$. The inoculum $\left(1 \mathrm{~cm}^{3}\right)$ was a suspension of spores $\left(5 \times 10^{7} \mathrm{~cm}^{3}\right)$ obtained by rinsing 7-day cultures of the fungal strains studied on the PDA slants with $5 \mathrm{~cm}^{3}$ of $0.9 \% \mathrm{NaCl}$. The cultures were incubated for 14 days in static conditions at $28{ }^{\circ} \mathrm{C}$. Control treatment consisted of cultures without the addition of dye substrates and non-inoculated medium.

\section{Determination of biosorption rate during decolorization}

Hyaline mycelium of 52 strains of microscopic fungi adsorbed Alizarin Blue Black B and alkali lignin during the experiment. After completion of the experiment, the mycelia were separated from the culture fluid by filtration, rinsing three times in sterile distilled water and refiltration. For the recovery of absorbed dye substances, the washed mycelium was transferred to Erlenmeyer flasks containing $50 \mathrm{~cm}^{3}$ of $70 \%$ ethanol and shaken $\left(150 \mathrm{rpm}, 28^{\circ} \mathrm{C}\right)$ in a water bath for $2 \mathrm{~h}$ (alkali lignin) or $24 \mathrm{~h}$ (Alizarin Blue Black B) (Zeroual et al. 2006). After this time, the mycelium was separated from the solution of the colored substances by centrifugation (6000 rev/min). The concentration of Alizarin Blue Black B $\left(A_{526 n m}\right)$ and alkali lignin $\left(A_{430 n m}\right)$ in the filtrate was assayed spectrophotometrically. The amount of dye substance absorption was determined on the basis of the difference in decolorization (1) and desorption of the test substances (2). Then, the percentage was calculated of the test substances biosorbed (3) during the decolorization process

$D=\frac{A i-A f}{A i} \times 100$

$A b=(D-A d s)$

$\% B=\frac{A b \times 100}{A i}$

where $D$-decolorization (in \%), $A i$-initial absorbance and $A f$-final absorbance for Alizarin Blue Black $\mathrm{B}$ at $A_{526 \mathrm{~nm}}$ and for the alkali lignin at $A_{430 \mathrm{~nm}}, A b$-amount of dye substrates sorbed by biomass (in \%), Ads-absorbance after desorption of dye substrates by ethanol.

\section{Mycelium sorption capacity}

The selected strains of microscopic fungi that effectively adsorb dye substrates were cultivated in static conditions in $100 \mathrm{~cm}^{3}$ Erlenmeyer flasks containing $50 \mathrm{~cm}^{3}$ of liquid PDA medium $\left(28^{\circ} \mathrm{C}\right)$. The inoculum $\left(2 \mathrm{~cm}^{3}\right)$ was a suspension of spores $\left(5 \times 10^{7} \mathrm{~cm}^{3}\right)$ obtained as described in point 2.3. After 7 days, the mycelia were separated from the media, rinsed 3 times in sterile water and aseptically transferred to the $0.03 \%$ aqueous solution of Alizarin Blue Black B, or $0.2 \%$ alkali lignin. The experiments were performed on a shaker $\left(130 \mathrm{rpm}\right.$ at $\left.28^{\circ} \mathrm{C}\right)$. The mycelia were transferred to $50 \mathrm{~cm}^{3}$ of $70 \%$ ethanol to determine the sorption capacity of the biomass and shaken for $24 \mathrm{~h}$ for Alizarin Blue Black $\mathrm{B}$ and $2 \mathrm{~h}$ for alkali lignin. The sorption capacity was estimated according to the equation:

$Q e=\frac{(\mathrm{Ci}-\mathrm{Cf}) V}{m}$

where $Q e$-biosorption capacity $\left(\mathrm{mg} \mathrm{g}^{-1}\right), C i$ and $C f$ initial and final concentration $\left(\mathrm{mg} \mathrm{l}^{-1}\right), m$-adsorbent dose (g), $V$-volume of solution (1).

\section{Biosorption optimization}

Biosorption experiments were carried out using $50 \mathrm{~cm}^{3}$ of dye compound solutions. In this study, we examined the effect of the initial biomass dose $(0.5 ; 1.0 ; 1.5 ; 2.0,2.5 \mathrm{~g})$, $\mathrm{pH}$ gradient (3.5-7.0, 0.5 unit increments) and temperature of incubation $\left(26,28,30,37^{\circ} \mathrm{C}\right.$ ) (Karthikeyan et al. 2009). The samples were incubated for 7 days on a shaker $(130 \mathrm{rpm})$ at $28{ }^{\circ} \mathrm{C}$. The measurements were taken after $24 \mathrm{~h}$ and 2, 3, 4, 5, 6 and 7 days. After this time, the mycelia were transferred to $50 \mathrm{~cm}^{3}$ of $70 \%$ ethanol and shaken for $24 \mathrm{~h}$ for Alizarin Blue Black B and $2 \mathrm{~h}$ for alkali lignin. The sorption capacity was estimated according to the aforementioned Eq. (4).

\section{Freundlich isotherm estimation}

The degree of biosorption, depending on the concentration of dye substrates, was determined by the Freundlich adsorption isotherm. The following concentrations were used for Alizarin Blue Black B: 50, 100, 150, 200, 250, $300 \mathrm{mg} \mathrm{l}^{-1}$, and for the lignin: 500, 1000, 1500, 2000 and $2500 \mathrm{mg} \mathrm{l}^{-1}$. Then, the $K_{\mathrm{F}}$ and $n$ parameters were determined, characterizing the model of sorption of Freundlich isotherms; linear regression analysis was used to determine specific curves of designated isotherms (5).

$\log Q e=\log K_{\mathrm{F}}+n \log C e$

where $Q e$ is the equilibrium value of sorbate uptake by the sorbent $\left(\mathrm{mg} \mathrm{g}^{-1}\right), C e$ is the equilibrium sorbate 
concentration in the solution, $K_{\mathrm{F}}\left(\mathrm{mg} \mathrm{g}^{-1}\right)$ are characteristic constants that indicate the extent of the biosorption, $n$ (dimensionless) indicates the heterogeneity of the adsorbent sites and the affinity between the adsorbate and the adsorbent; the higher the value of $\mathrm{n}$, the higher the heterogeneity and affinity.

\section{Statistical analysis}

All the experiments were carried out in triplicate, and data presented are the mean values of three independent experiments. Statistical analysis and graphical representation were done in GraphPad Prism version 5.0. One-way ANOVA and the differences in means between the samples were determined using the Tukey test. $P$ values below 0.05 were considered significant. For homogeneity of variances were used Levene's and Brown-Forsythe tests. The F-ratio in an ANOVA shows the variation due to the applied treatment relative to the variation caused by experimental error. A statistically significant F-ratio signifies that the null hypothesis should be rejected and that means the biosorption of anthraquinone dye and alkali lignin depends of sorption conditions. The relationships between the biosorption rate, fungal biomass and dye compound concentrations were analyzed using the regression method, determining the function of curvilinear regression and the $\mathrm{R}^{2}$ coefficient of determination.

\section{Results and discussion}

\section{Evaluation of biosorption capacity of microscopic fungi cultures}

The mycelium ability to absorb synthetic dyes, alkali lignin and other colored compounds found in industrial sewage, dyestuff and pulp or paper mills has been already indicated earlier by many authors (Anastasi et al. 2009; Grainger et al. 2011; Karthikeyan et al. 2009; Sadhasivam et al. $2005,2007,2010)$. Sorption of dyes by mycelium is considered by some authors as the initial stage of industrial wastewater decolorization with the participation of fungi (Aretxage et al. 2001). Living biomass of Aspergillus niger, Trichoderna harzianum, Fusarium sp. and Penicillium sp. should be particularly considered as effective sorbents of dye substances (Fu and Viraraghavan 2000; Sadhasivam et al. 2005, 2007; Seyis and Subasioglu 2008; Xin et al. 2010; Yang et al. 2011). The results of our study indicate that all the 52 tested strains during the 14-day culture period exhibited the ability to biosorp anthraquinone dye and alkali lignin. The degree of biosorption was dependent on the strain of the fungus. The largest differences in the sorption properties were observed in the case
Table 1 Contribution of biosorption process in removal of $0.03 \%$ anthraquinone dye Alizarin Blue Black B (ABBB) and $0.2 \%$ alkali lignin (AL) by selected strains of microscopic fungi

\begin{tabular}{|c|c|c|c|c|c|c|}
\hline \multirow[t]{3}{*}{ Strains } & \multicolumn{6}{|c|}{ Biosorption rate (in \%) } \\
\hline & \multicolumn{3}{|l|}{$\overline{\mathrm{AL}}$} & \multicolumn{3}{|c|}{$\mathrm{ABBB}$} \\
\hline & $0-10 *$ & $11-20$ & $21-30$ & $0-10$ & $11-20$ & $21-30$ \\
\hline H. haematococca & $6 * *$ & 10 & 9 & 7 & 8 & 10 \\
\hline G. catenulatum & 5 & 7 & 4 & 4 & 7 & 5 \\
\hline G. roseum & 2 & 2 & 1 & 3 & 1 & 1 \\
\hline Aspergillus sp. & 2 & 1 & & 2 & 1 & \\
\hline T. harzianum & & 1 & & & 1 & \\
\hline A. spinosa & 1 & & & & 1 & \\
\hline Ph. cyclosporus & 1 & & & & 1 & \\
\hline
\end{tabular}

*\% of biosorption, ** number of strains

of $H$. haematococca-most frequently represented among the analyzed fungi. The degree of biosorption of alkali lignin in the cultures of this specie, depending on the strain, ranged from 8-9 to 20-25\% (Table 1).

Among the tested strains, some mycelia of H. haematococca and G. catenulatum absorbed the highest dye percentages (21-30\%), while the least Aspergillus sp.

H. haematococca BwIII43, $\mathrm{K} 37$ and T. harzianum BsIII33 demonstrated the highest sorption properties in the collection of 52 strains of microscopic fungi. The results of our study indicate that after 7 days the living biomass of $H$. haematococca $\mathrm{K} 37$ absorbed $247.05 \mathrm{mg} \mathrm{g}^{-1} \mathrm{ABBB}$ (Fig. 1a). This indicates stronger sorption properties toward anthraquinone dyes in comparison with other microscopic fungi. Comparable amount of anthraquinone dye biosorption Yang et al. (2011) received only in the experiment with Penicillium. Author reported that the biomass of the Penicillium YW 01 absorbed Acid Black 172 (anthraquinone dye) in optimal conditions in a yield of $225.38 \mathrm{mg} \mathrm{g}^{-1}$. Research of Fu and Viraraghavan (2000) showed that the living biomass of $A$. niger removed Basic Blue 9 after 2 days with a yield of only $1.17 \mathrm{mg} \mathrm{g}^{-1}$. On the other hand, Seyis and Subasioglu (2008) reported the most efficient sorption of Methyl Orange (azo dye) $\left(100 \mathrm{mg} \mathrm{dm}^{-3}\right)$ by the mycelium of $T$. harzianum and Fusarium sp. to be at $30 \%\left(30 \mathrm{mg} \mathrm{dm}^{-3}\right)$ and $45-70 \%$ (45-70 $\mathrm{mg} \mathrm{dm}^{-3}$ ) after 5 days of incubation. Our experiments showed that the mycelium biosorption of Alizarin Blue Black B (300 $\left.\mathrm{mg} \mathrm{l}^{-3}\right)$ and post-industrial (2000 $\mathrm{mg} \mathrm{l}^{-3}$ ) lignin of the study strains was significantly different $(\mathrm{p}<0.001)$. Alizarin Blue Black B (ABBB) and alkali lignin (AL) were most effectively absorbed after 7 days, and the mycelium of $H$. haematococca K37 was characterized by the highest sorption capacity against both dye substances (235.27 and $162.86 \mathrm{mg} \mathrm{g}^{-1}$, respectively) (Fig. 1a, b). 

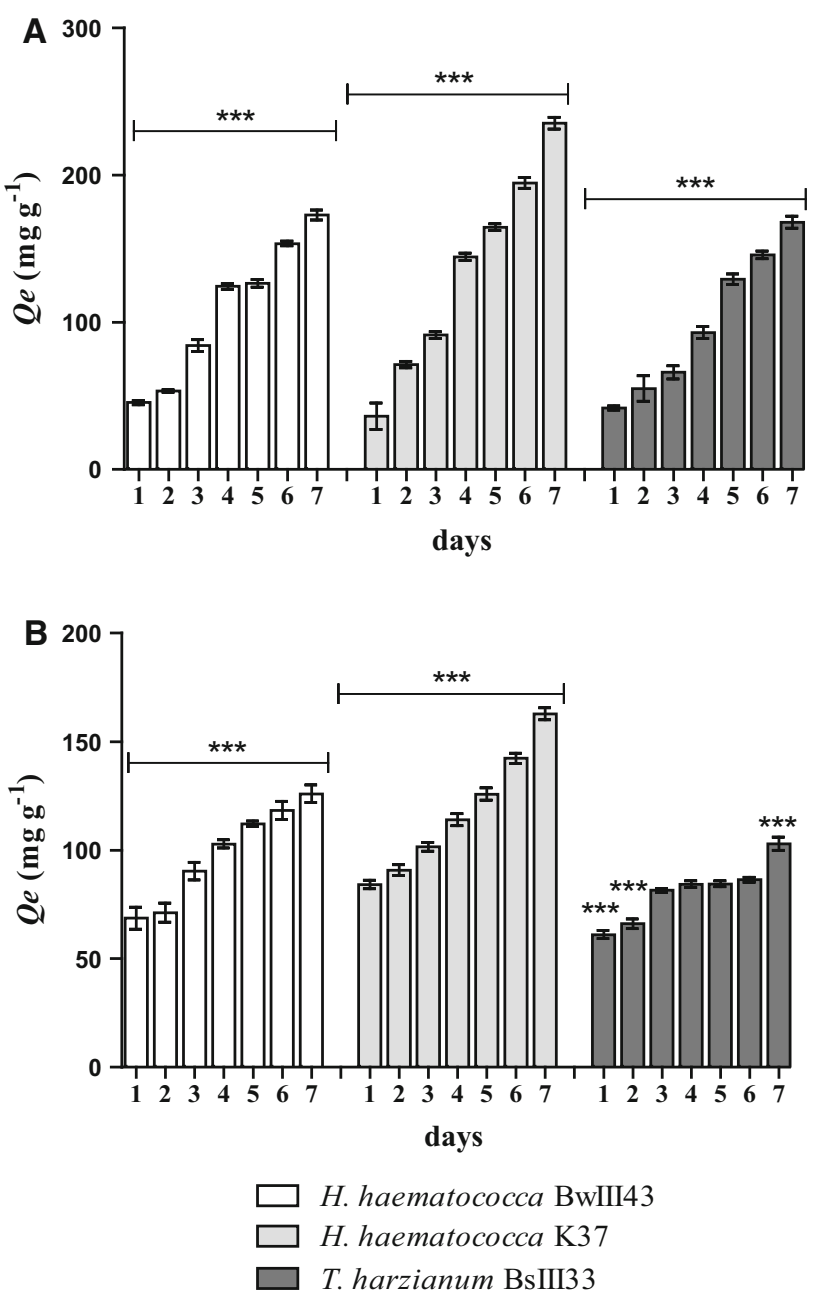

Fig. 1 Effect of time on biosorption capacity of microscopic fungi biomass for Alizarin Blue Black B (a) and alkali lignin (b). The significant difference between biosorption rate in the presence of fungal biomass was calculated using one-way ANOVA and postTukey test. The histogram shows mean values \pm SD from three independent experiments, $* * * p<0.001$

\section{Optimal biosorption conditions}

As in the case of enzymatic decolorization with the participation of extracellular fungal oxidoreductases, biosorption process also requires the selection of appropriate parameters (Karthikeyan et al. 2009; Seyis and Subasioglu 2008; Yang et al. 2012). This process involves various functional groups, such as $-\mathrm{NH}_{3}{ }^{+},-\mathrm{COO}^{-}$and $-\mathrm{HPO}_{3}{ }^{-}$, which are part of polysaccharides, mainly chitin, but also proteins and lipids of fungal cell walls (Yang et al. 2012). The efficiency of this process also depends on the chemical structure of the dyes and environmental conditions (Aksu 2005). Our results show that the amount of fresh fungal biomass has a significant impact on the process of biosorption $(p<0.001)$. The highest rate of biosorption was observed when $1 \mathrm{~g}$ of fresh mycelium was used
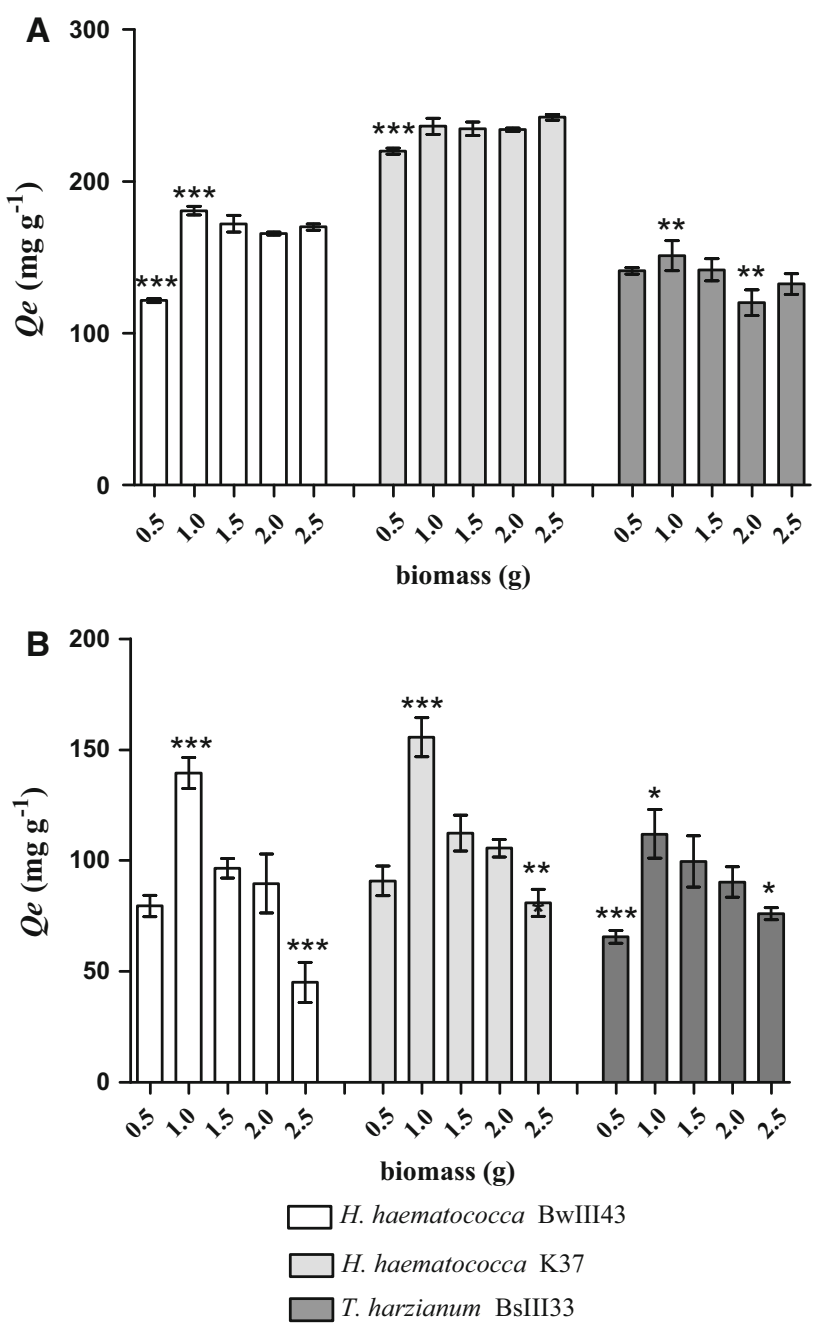

Fig. 2 Effect of biomass dose on biosorption capacity of microscopic fungi for Alizarin Blue Black B (a) and alkali lignin (b). The significant difference between biosorption rate in the presence of fungal biomass was calculated using one-way ANOVA and postTukey test. The histogram shows mean values \pm SD from three independent experiments. $* * * p<0.001 ; * * p<0.01 ; * p<0.05$

(Fig. 2a, b). Sorption properties of the living biomass were significantly lower $(p<0.001)$ when the temperature of the process exceeded $30{ }^{\circ} \mathrm{C}$ (Fig. 3a, b). All of the three tested strains (H. haematococca BwIII43 and T. harzianum BsIII33) had similar sorption properties in the temperature range of $26-30{ }^{\circ} \mathrm{C}$. In contrast, the $H$. haematococca $\mathrm{K} 37$ strain exhibited a significantly higher $(p<0.001)$ degree of biosorption at $28{ }^{\circ} \mathrm{C}$. Maximum absorption of both dye substrates was observed in $H$. haematococca strains (190-247 and 153-161 $\mathrm{mg} \mathrm{g}^{-1}$, respectively) (Fig. 3a, b). Therefore, the temperature of $28^{\circ} \mathrm{C}$ for the biosorption process was adopted as optimal in further experiments. Our research indicated that the biosorption process of Alizarin Blue Black B and alkali lignin decreased when the temperature reached $37{ }^{\circ} \mathrm{C}$. Our results are consistent with the study of Sadhasivam et al. (2010). The latter authors report 


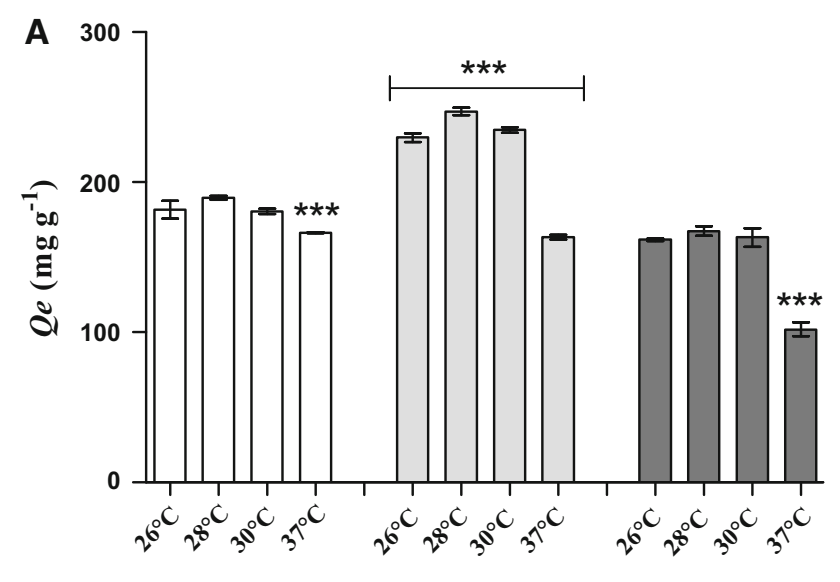

temperature

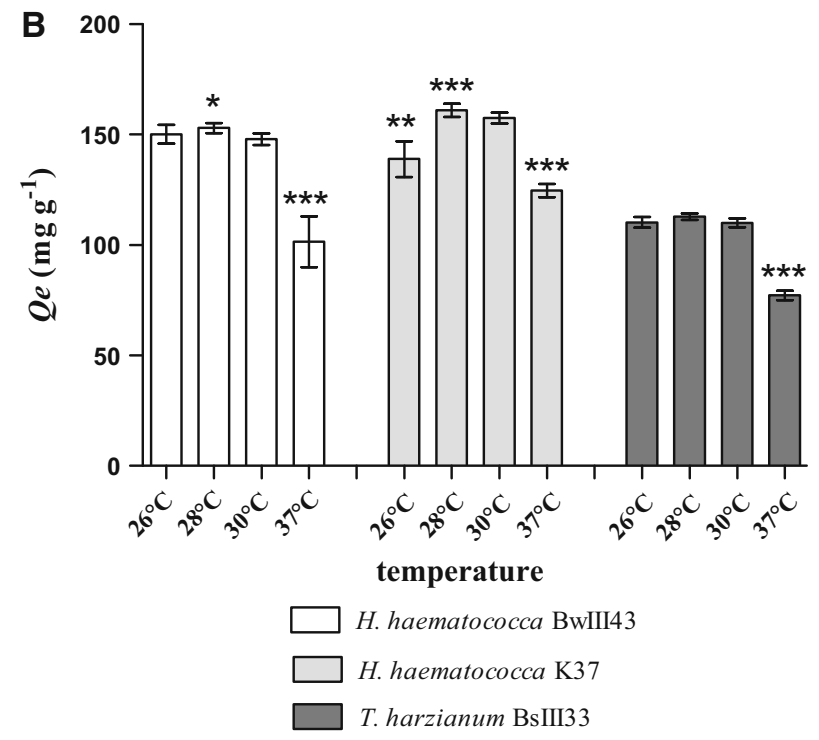

Fig. 3 Effect of initial temperature on biosorption capacity of microscopic fungi biomass for Alizarin Blue Black B (a) and alkali lignin (b). The significant difference between biosorption rate in the presence of fungal biomass was calculated using one-way ANOVA and post-Tukey test. The histogram shows mean values \pm SD from three independent experiments. $* * * p<0.001$; $* * p<0.01 ; * p<0.05$

that the sorption of Remazol Brilliant Blue $\mathrm{R}$ (anthraquinone dye) by the living mycelium of $T$. harzianum was the highest at $28{ }^{\circ} \mathrm{C}$ (Sadhasivam et al. 2010). On the other hand, studies of other authors show that the living mycelium of various fungi (Rhizopus nigricans, A. niger, T. harzianum and Fusarium sp.) most effectively absorbed these substances in the range of $20-30{ }^{\circ} \mathrm{C}$ (Kumari and Abraham 2007; Seyis and Subasioglu 2008; Karthikeyan et al. 2009; Sadhasivam et al. 2010). However, that work did not provide any information on the relationship between the temperature and the absorption of lignin by the mycelium. Nevertheless, research on the biosorption of related lignin high aromatic polymers, such as humic acids by the Rhizopus arrhizus biomass, indicates that this process is more effective at lower temperatures, i.e., $16-26{ }^{\circ} \mathrm{C}$ (Zhou and Banks 1993). In addition, biosorption of low molecular weight aromatic compounds, such as phenols or PAHs by the mycelium of Phanerochaete chrysosporium and $F$. solani, occurred efficiently at $24-25^{\circ} \mathrm{C}$ (Thion et al. 2012; Wu and Yu 2006). Zhou and Banks (1993) claimed that the biological sorption at lower temperatures in the range of $16-26{ }^{\circ} \mathrm{C}$ is a physical process, which does not require the presence of energy. In contrast, at higher temperatures $\left(36{ }^{\circ} \mathrm{C}\right)$, sorption is based on chemical reactions (chemisorption) and requires the presence of metabolic energy. Therefore, a decrease in the biosorption of ABBB and alkali lignin at $37{ }^{\circ} \mathrm{C}$, and the maximum biosorption at $28{ }^{\circ} \mathrm{C}$, proves the physical nature of this process.

The critical $\mathrm{pH}$ is among the environmental factors that determine the interaction between the dye substance and the mycelium. As it is known, the concentration of $\mathrm{H}^{+}$or $\mathrm{OH}^{-}$is changing cell polarization, and thus, the binding of dyes. As regards the $\mathrm{pH}$, sorption of dye substances increased with increasing $\mathrm{pH}$ and reached significantly higher $(p<0.001)$ levels at $\mathrm{pH}=7.0$ (Fig. $4 \mathrm{a}, \mathrm{b}$ ). It was found, based on the results obtained for the biosorption process of anthraquinone dye and alkali lignin, that the maximum biosorption was observed at $\mathrm{pH} 7.0$ (temperature $28{ }^{\circ} \mathrm{C}$ ). Under these conditions, the biomass of the $H$. haematococca $\mathrm{K} 37$ strain was characterized by the highest sorption capacity toward Alizarin Blue Black B and alkali lignin, (247.05 and $161.00 \mathrm{mg} \mathrm{g}^{-1}$, respectively) (Fig. 4a, b). The obtained results (Fig. 4a) also indicate that Alizarin Blue Black B used in this work is anionic anthraquinone dye was adsorbed from highly acid to neutral medium $\mathrm{pH}$ (3.0-7.0). This confirms other author reports that microscopic fungi can bind anionic dyes in a wide $\mathrm{pH}$ range (Kumari and Abraham 2007; O'Mahony et al. 2002; Yang et al. 2011, 2012). Yang et al. $(2011,2012)$ in the studies on Reactive Black 5, Congo Red and Acid Black 172 binding by the mycelium of Penicillium commune YW01, reported the possibility of dye biosorption under strongly acidic conditions $(\mathrm{pH}$ 1.0-3.0). Authors report that in acidic environment for the binding of anionic dyes are responsible amino groups of fungi. On the other hand, $\mathrm{Fu}$ and Viraraghavan (2002b) and Kumari and Abraham (2007) reported that microscopic fungi Rhizopus sp. and Aspergillus sp. efficiently absorbed anionic dyes, such as Reactive Black 8, Reactive Green 19 and Reactive Blue 38 at $\mathrm{pH}=6.0$. According to Sadhasivam et al. (2007), different $\mathrm{pH}$ optima for the biosorption of anionic dyes by various fungi are primarily due to the different number of positively charged sites on the surface of mycelium biomass. Microscopic fungi have different isoelectric points $(\mathrm{pI}=1.0-6.0)$ and thus different optimum $\mathrm{pH}$ for binding the dye (Kumari and Abraham 2007; O'Mahony et al. 2002; Yang et al. 2011, 2012). Based on the results of own 
Fig. 4 Effect of initial $\mathrm{pH}$ on biosorption capacity of microscopic fungi biomass for Alizarin Blue Black B (a) and alkali lignin (b). The significant difference between biosorption rate in the presence of fungal biomass was calculated using one-way ANOVA and postTukey test. The histogram shows mean values \pm SD from three independent experiments. $* * * p<0.001, * * p<0.01$, $* p<0.05$
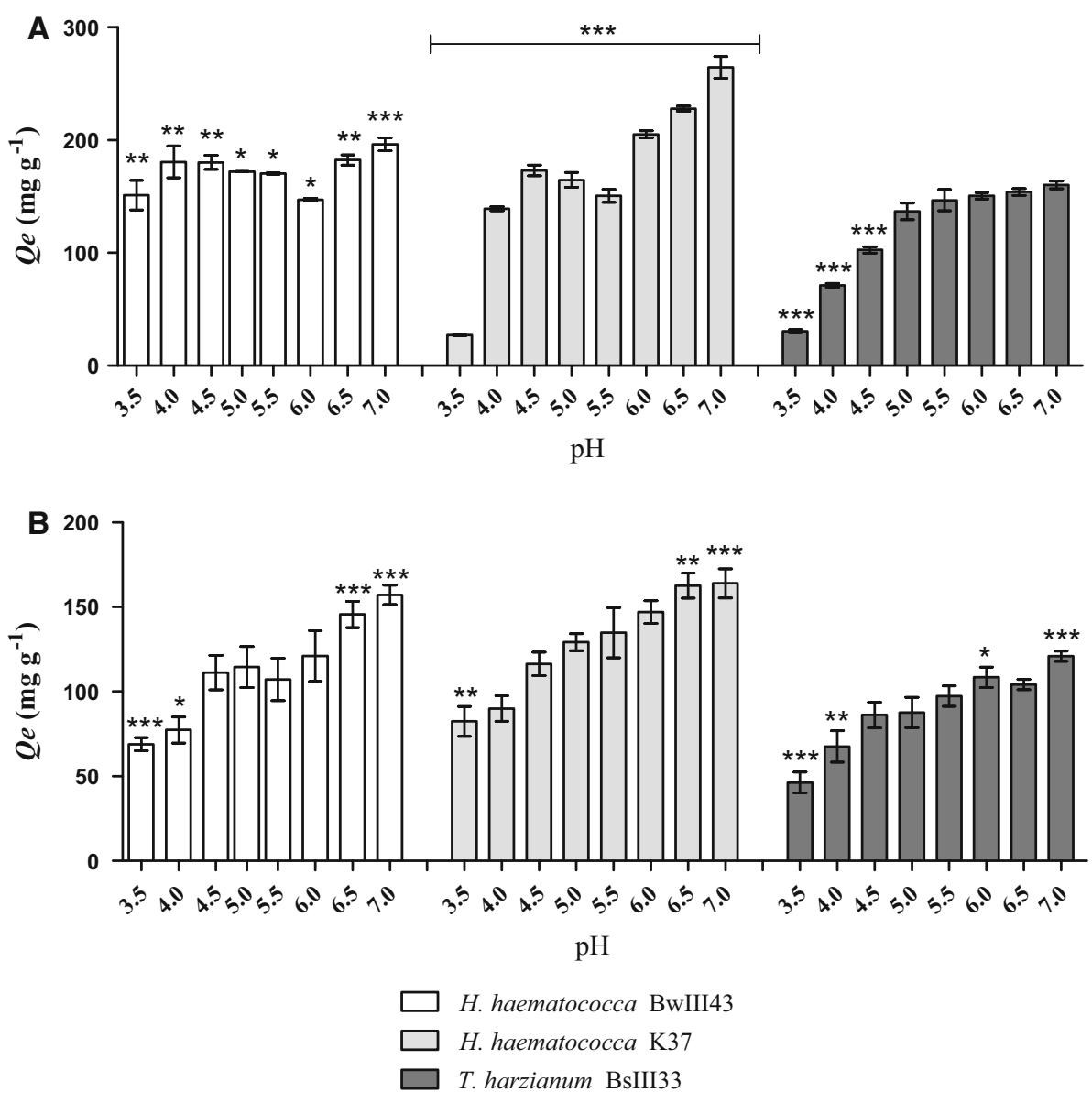

studies, it was found that the yield of biosorption of Alizarin Blue Black $\mathrm{B}$ increased with the $\mathrm{pH}$, reaching a maximum at $\mathrm{pH}$ 7.0. Therefore, it can be assumed that within a certain $\mathrm{pH}$ range (3.0-7.0), the mycelium had a positive charge, while the isoelectric point (pI), above which the number of negatively charged sites exceeds the number of positive sites on the surface of the mycelium is above $\mathrm{pH}$ 7.0. In the available literature, there are no data concerning the optimum $\mathrm{pH}$ for lignin biosorption. The results of this study indicate that the microscopic fungi studied can grow and effectively decolorize alkali lignin at $\mathrm{pH} 7.0$ and above within the $\mathrm{pH}$ range of 7.5-10.0 (data not shown). This effect has been achieved in relation to the tested anthraquinone dye (data not show). The ability of these microfungi to grow in an alkaline environment is an advantage from a practical point of view. This is due to the fact that many dye industrial wastewater is alkaline (Da Re and Papinutti 2011; Garg and Tripathi 2011). Therefore, obtaining strains, such as $H$. haematococca, effectively decolourizing the dyes and alkali lignin under alkaline conditions, is a major achievement in this field. It has been previously (Knapp et al. 1999; Swamy and Ramsay 1999) reported that the addition of dyes to the medium increases the $\mathrm{pH}$, which reduces the efficiency of decolorization.

\section{Freundlich isotherm}

We have also determined the relationship between the degree of absorption and the concentration of mycelia, expressed as the Freundlich adsorption isotherm. Linear relationships between the $0.03 \%$ Alizarin Blue Black B and $0.2 \%$ alkali lignin and the mycelium biomass of selected strains $\left(1 \mathrm{~g}\right.$ of mycelium biomass, $28^{\circ} \mathrm{C}$, $\mathrm{pH}=7.0$ ) were determined in the solution in the conditions optimized for biosorption. Based on the values of the $K_{\mathrm{F}}$ and $n$ constants, characterizing the Freundlich adsorption isotherm model, we described sorption properties of mycelium to Alizarin Blue Black B and alkali lignin and the strength of the interaction between the substrate and adsorbent (Figs. 5, 6).

On the basis of the graphical presentation of data (Fig. 6), it can be concluded that there was a positive correlation between the measured traits, as with increasing concentration of dye substances in the solution, the absorption of these substances by the mycelium was also increasing. The selected model of Freundlich adsorption isotherms in more than $90 \%$ explained the relationship between the increasing concentrations of dye substance and the sorption capacity of mycelium biomass of the test 

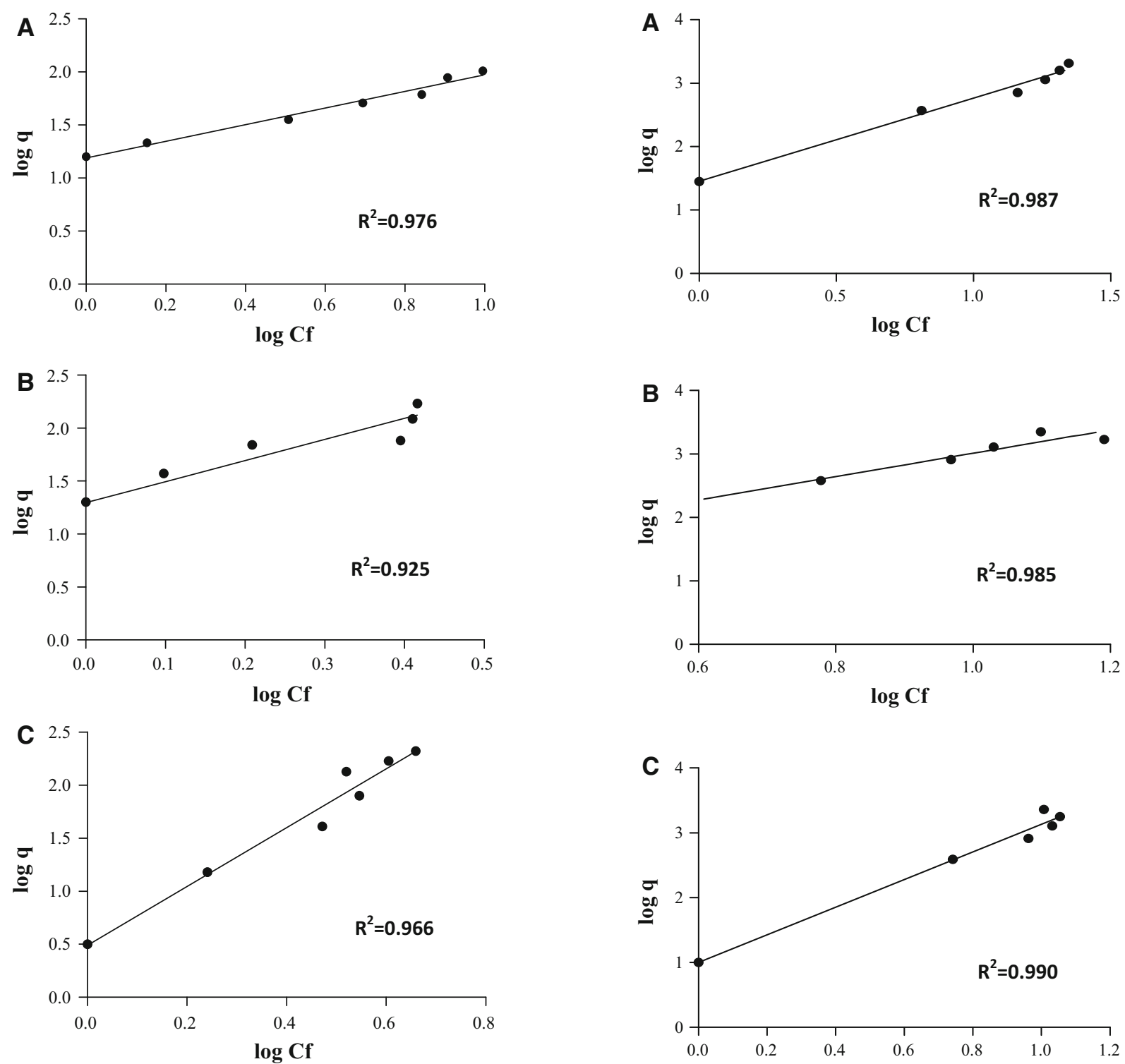

Fig. 5 Freundlisch isotherm for the removal of anthraquinone dye Alizarin Blue Black B (ABBB) by H. haematococca BwIII43 (a), $H$. haematococca $\mathrm{K} 37$ (b), T. harzianum BsIII33 (c)

strains (Table 2). The highest sorption properties toward anthraquinone dye were shown for the mycelial of $H$. haematococca $\mathrm{K} 37$ and BwIII43, which $K_{\mathrm{F}}$ constant were 19.96 and $15.85 \mathrm{mg} \mathrm{g}^{-1}$, respectively. The test strains were also characterized by a strong interaction between Alizarin Blue Black B and the biomass. The efficiency of binding of this dye in the case of the H. haematococca BwIII43 strain was approximately 2.5 -fold greater $(n=1.27)$. In the presence of alkali lignin, the highest sorption capacity and bond strength exhibited the mycelium of $H$. haematococca BwIII43 ( $\left.K_{\mathrm{F}}=28.20 \mathrm{mg} \mathrm{g}^{-1}, n=3.46\right)$ (Table 2). The efficiency of absorption of alkali lignin by the mycelium of H. haematococca $\mathrm{K} 37$ and the strength of its interaction with a substrate were, respectively, about twofold

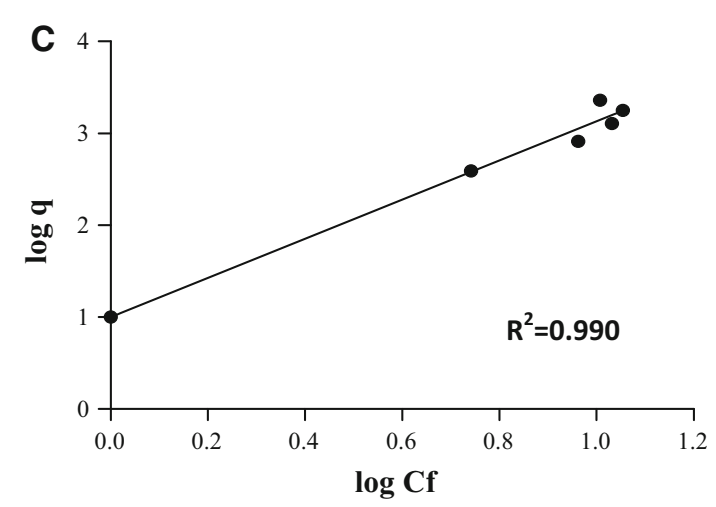

Fig. 6 Freundlisch isotherm for the removal of alkali lignin by $H$. haematococca BwIII43 (a), H. haematococca K37 (b), T. harzianum BsIII33 (c)

$\left(K_{\mathrm{F}}=14.80 \mathrm{mg} \mathrm{g}^{-1}\right)$ and 4.5-fold lower $(n=0.75)$. Among the studied strains, the biomass of T. harzianum BsIII33 showed the weakest sorption properties. Sorption capacity of the biomass of $T$. harzianum BsIII33 was several fold lower $(n=0.29$ and 0.34$)$ as compared with other strains (Table 2). It was found that the biomass of $H$. haematococca BwIII43 and K37 had larger possibility of Alizarin Blue Black B sorption in comparison with $T$. harzianum BsIII33 ( $K_{\mathrm{F}}=15.85$, and $19.96 \mathrm{mg} \mathrm{g}^{-1}$ and $K_{\mathrm{F}}=3.17 \mathrm{mg} \mathrm{g}^{-1}$, respectively). Our research also shows that the mycelium of $H$. haematococca showed stronger affinity to Alizarin Blue Black B ( $n=1.27$ and 0.48$)$ than the $T$. harzianum mycelium $(n=0.29)$. A weaker 
Table 2 Biosorption isotherm parameters for adsorption anthraquinone dye Alizarin Blue Black B (ABBB) and alkali lignin (AL) by selected strains of microscopic fungi

\begin{tabular}{|c|c|c|c|c|c|c|}
\hline \multirow[t]{3}{*}{ Strains } & \multicolumn{6}{|c|}{ Freundlich constants } \\
\hline & \multicolumn{3}{|l|}{ AL } & \multicolumn{3}{|c|}{ ABBB } \\
\hline & $K_{\mathrm{F}}$ & $\mathrm{n}$ & $R^{2}$ & $K_{\mathrm{F}}$ & $\mathrm{n}$ & $R^{2}$ \\
\hline H. haematococca BwIII43 & 28.20 & 3.46 & 0.987 & 15.85 & 1.27 & 0.976 \\
\hline H. haematococca $\mathrm{K} 37$ & 14.80 & 0.75 & 0.985 & 19.96 & 0.48 & 0.925 \\
\hline T. harzianum BsIII33 & 9.79 & 0.34 & 0.990 & 3.17 & 0.29 & 0.966 \\
\hline
\end{tabular}

$K_{\mathrm{F}}\left(\mathrm{mg} \mathrm{g}^{-1}\right)$ and $\mathrm{n}$ are characteristic constants that indicate the extent of the biosorption and degree of nonlinearity between the concentration of solution and biosorption, respectively; $R^{2}$ - the coefficient of determination (linear regression) adsorption possibility of the mycelium of $T$. harzianum WL1 ( $1 \mathrm{~g}$ of biomass) in comparison with the mycelium of other species of fungi was also shown by Sadhasivam et al. $(2005,2007)$ for Rhodamine 6B and Trypan Blue. Grainger et al. (2011) have identified a higher sorption capacity of inactivated mycelia of Aspergillus niger to pulp and paper effluent rich in lignin, in the conditions optimized for biosorption, with a maximum value reaching $84.99 \mathrm{mg} \mathrm{g}^{-1}$.

\section{Conclusion}

According to the obtained results, it can be concluded that the biosorption of dye aromatic compounds complements biodecolorization process involving extracellular oxidoreductases. When selecting optimal parameters for decolorization, i.e., biodegradation of these compounds by microscopic fungi, one should also consider their sorption capacity. It is mainly the ability to grow in a wide range of $\mathrm{pH}$ and adsorption capacity, similar, and in some cases even better, than the natural or commercially available sorbents. Microscopic fungi studied in the present work have a high potential for application in terms of biodecolorization of industrial wastewater.

Acknowledgments This work was partially funded by the Polish National Science Center (project No. N304 292440).

Open Access This article is distributed under the terms of the Creative Commons Attribution 4.0 International License (http:// creativecommons.org/licenses/by/4.0/), which permits unrestricted use, distribution, and reproduction in any medium, provided you give appropriate credit to the original author(s) and the source, provide a link to the Creative Commons license, and indicate if changes were made.

\section{Abbreviations}

$\begin{array}{ll}\text { ABBB } & \text { Alizarin Blue Black B } \\ \text { AL } & \text { Alkali lignin } \\ \text { PDA } & \text { Glucose-potato media }\end{array}$

\section{References}

Aksu Z (2005) Application of biosorption for removal of organic pollutants: a review. Process Biochem 40:997-1026

Ali I (2010) The quest for active carbon adsorbent substitutes: inexpensive adsorbents for toxic metal ions removal from wastewater. Sepn Purfn Rev 39:95-171

Ali I (2012) New generation adsorbents for water treatment. Chem Revs 112:5073-5091

Ali I (2014) Water treatment by adsorption columns: evaluation at ground level. Sepn Purfn Rev 43:175-205

Ali I, Gupta VK (2007) Advances in water treatment by adsorption technology. Nat Protocols 1:2661-2667

Ali I, Asim M, Khan TA (2012) Low cost adsorbents for removal of organic pollutants from wastewater. J Environ Manage 113:170-183

Almeida EJR, Corso CR (2014) Comparative study of toxicity of azo dye Procion Red MX-5B following biosorption and biodegradation treatments with the fungi Aspergillus niger and Aspergillus terreus. Chemosphere 112:312-317

Anastasi A, Pirigione V, Casieri L, Varese GC (2009) Decolourisation of model and industrial dyes by mitosporic fungi in different culture condition. World J Microbiol Biotechnol 25:1363-1374

Aretxage A, Romero S, Sarr M, Vincent T (2001) Adsorption step in the biological degradation of a textile dye. Biotechnol Prog 17:664-668

Banat IM, Nigam P, Singh D, Marchant R (1996) Microbial decolorization of textile-dye-containing effluents: a review. Bioresour Technol 58:217-227

Bayramoglu G, Arica MY (2007) Biosorption of benzidine based textile dyes Direct Blue 1 and Direct Red 128 using native and heat-treated biomass of Trametes versicolor. J Hazard Mater 143:135-143

Crini G (2006) Non-conventional low-cost adsorbents for dye removal: a review. Bioresour Technol 97:1061-1085

Da Re V, Papinutti L (2011) Black Liquor decolorization by white-rot fungi. Appl Biochem Biotechnol 165:406-415

Fomina M, Gadd GM (2014) Biosorption: current perspectives on concept, definition and application. Bioresour Technol 160:3-14

$\mathrm{Fu}$ Y, Viraraghavan $\mathrm{T}$ (2000) Removal of a dye from an aqueous solution by fungus Aspergillus niger. Water Quality Res J Canada 35:95-111

Fu Y, Viraraghavan T (2001) Fungal decolorization of dye wastewaters: a review. Bioresour Technol 79:251-262

Fu Y, Viraraghavan T (2002a) Dye biosorption sites in Aspergillus niger. Bioresour Technol 82:139-145

Fu Y, Viraraghavan T (2002b) Removal of Congo Red from an aqueous solution by fungus Aspergillus niger. Adv Environ Res 7:239-247 
Gallagher KA, Healy MG, Allen SJ (1997) Biosorption of synthetic dye and metal ions from aqueous effluents using fungal biomass. In: Wise DL (ed) Global environmental biotechnology. Elsevier, London, pp 27-50

Garg SK, Tripathi M (2011) Strategies of decolorization and detoxification of Pulp and Paper mill effluents. Rev Environ Contam Toxicol 212:113-135

Grainger S, Fu GY, Hall ER (2011) Biosorption of colour-imparting substances in biologically treated pulp mill effluent using Aspergillus niger fungal biomass. Water Air Soil Pollut 217:233-244

Karthikeyan K, Nanthakumar K, Lakshmanaperumalsamy P (2009) Kinetic and equilibrium studies on in situ biosorption of Reactive Blue 140 dye by live biomass preparation of Aspergillus niger HM11. Global J Environ Res 3:264-273

Knapp JS, Zhang F, Tapley KN (1999) Decolourization of orange II by a wood-rotting fungus. $\mathrm{J}$ Chem Technol Biotechnol 69:289-296

Korniłłowicz-Kowalska T, Rybczyńska K (2014) Screening of microscopic fungi and their enzyme activities for decolorization and biotransformation of some aromatic compounds. Int $\mathrm{J}$ Environ Sci Technol 12:2673-2686

Kumari K, Abraham TE (2007) Biosorption of anionic textile dyes by nonviable biomass of fungi and yeast. Bioresour Technol 98:1704-1710

Mona S, Kaushik A, Kaushik CP (2011) Biosorption of reactive dye by waste biomass of Nostoc linckia. Ecol Eng 37:1589-1594

Nigam P, Armour G, Banat JM, Singh D, Marchant R (2000) Physical removal of textile dyes from effluents and solid-state fermentation of dye-adsorbed agricultural residues. Bioresour Technol 72:219-226

O'Mahony T, Guibal E, Tobin JM (2002) Reactive dye biosorption by Rhizopus arrhizus biomass. Enzyme Microb Technol 31:456-463

Polman A, Brekenridge CR (1996) Biomass-mediated binding and recovery of textile dyes from waste effluents. Text Chem Color 28:31-35

Reife A, Freeman HS (1996) Carbon adsorption of dyes and selected intermediates. Wiley, New York

Robinson T, McMullan G, Marchant R, Nigam P (2001) Remediation of dyes in textile effluent: a critical review on current treatment technologies with a proposed alternative. Bioresour Technol 77:247-255

Rybczyńska K, Korniłłowicz-Kowalska T (2015) Evaluation of dye compounds' decolorization capacity of selected $H$. haematococca and T. harzianum strains by principal component analysis (PCA). Water Air Soil Pollut. doi:10.1007/s11270-015-2473-8
Sadhasivam S, Saritha E, Savitha S, Swaminathan K (2005) Comparison of the efficacy of live and autoclaved mycelium of Trichoderma harzianum on the removal of Trypan Blue. Bull Environ Contam Toxicol 75:1046-1053

Sadhasivam S, Savitha S, Swaminathan K (2007) Exploitation of Trichoderma harzianum mycelia waste for the removal of rhodamine $6 \mathrm{G}$ from aqueous solution. $\mathrm{J}$ Environ Manag $85: 155-161$

Sadhasivam S, Savitha S, Swaminathan K, Lin F-H (2010) Biosorption of RBBR by Trichoderma harzianum WL1 in stirred tank and fluidized bed reactor models. J Taiwan Ins Chem Eng 41:326-332

Seyis I, Subasioglu T (2008) Comparison of live and dead biomass of fungi on decolorization of methyl orange. African J Biotechnol 7:2212-2216

Swamy J, Ramsay JA (1999) The evaluation of white rot fungi in the decolorization of textile dyes. Enzyme Microb Technol 24:130-137

Thion C, Cébron A, Buguirisain T, Leyval C (2012) PAH biotransformation and sorption by Fusarium solani and Arthrobacter oxydans isolated from a polluted soil in axenic cultures and mixed co-cultures. Int Biodeterior Biodegrad 68:28-35

Wu J, Yu HQ (2006) Biosorption of phenol and chlorophenols from aqueous solutions by fungal mycelia. Process Biochem 41:44-49

Xin B, Chen G, Zheng W (2010) Bioaccumulation of Cu-complex reactive dye by growing pellets of Penicillium oxalicum and its mechanism. Water Res 44:3565-3572

Yang Y, Wang G, Wang B, Li Z, Jia X, Zhou Q, Zhau Y (2011) Biosorption of Acid Black 172 and Congo Red from aqueous solution by nonviable Penicillium YW01: kinetic study, equilibrium isotherm and artificial neural network modeling. Bioresour Technol 102:828-834

Yang Y-Y, Li Z-L, Wang G, Zhao X-P, Crowley DE, Zhao Y-H (2012) Computational identification and analysis of key biosorbent characteristics for the biosorption process of Reactive Black 5 onto fungal biomass. PLoS ONE 7:e33551

Zeroual Y, Kim BS, Kim CS, Balghen M, Lee KM (2006) Biosorption of bromophenol blue from aqueous solutions by Rhizopus stolonifer biomass. Water Air Soil Pollut 177:135-146

Zhou JL, Banks CJ (1991) Removal of humic acid fraction by Rhizopus arrhizus: uptake and kinetic studies. Environ Technol 12:859-869

Zhou JL, Banks CJ (1993) Mechanism of humic acid color removal from natural waters by fungal biomass biosorption. Chemosphere 27:607-620 